\title{
Wnt/ $\beta$-catenin signaling contributes to articular cartilage homeostasis through lubricin induction in the superficial zone
}

\author{
Fengjun Xuan', Fumiko Yano², Daisuke Mori², Ryota Chijimatsu ${ }^{1,2}$, Yuji Maenohara', Hideki Nakamoto', \\ Yoshifumi Mori ${ }^{1,3}$, Yuma Makii ${ }^{1}$, Takeshi Oichi ${ }^{1}$, Makoto Mark Taketo ${ }^{4}$, Hironori Hojo ${ }^{5}$, Shinsuke Ohba', \\ Ung-il Chung ${ }^{5}$, Sakae Tanaka ${ }^{1}$ and Taku Saito ${ }^{1 *}$ (D)
}

\begin{abstract}
Background: Both loss- and gain-of-function of Wnt/ $\beta$-catenin signaling in chondrocytes result in exacerbation of osteoarthritis (OA). Here, we examined the activity and roles of Wnt/ß-catenin signaling in the superficial zone (SFZ) of articular cartilage.

Methods: Wnt/ $\beta$-catenin signaling activity was analyzed using TOPGAL mice. We generated Prg4-Cre ${ }^{E R T 2} ; C_{t n n b} 1^{f l f f l}$

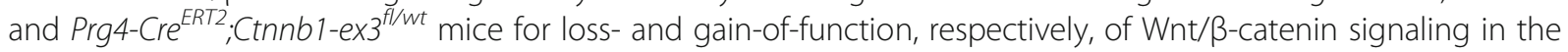
SFZ. Regulation of Prg4 expression by Wnt/ $\beta$-catenin signaling was examined in vitro, as were upstream and downstream factors of Wnt/ $\beta$-catenin signaling in SFZ cells.
\end{abstract}

Results: Wnt/ $\beta$-catenin signaling activity, as determined by the TOPGAL reporter, was high specifically in the SFZ of mouse adult articular cartilage, where Prg4 is abundantly expressed. In SFZ-specific $\beta$-catenin-knockout mice, OA development was significantly accelerated, which was accompanied by decreased Prg4 expression and SFZ destruction. In contrast, Prg4 expression was enhanced and cartilage degeneration was suppressed in SFZ-specific $\beta$-catenin-stabilized mice. In primary SFZ cells, Prg4 expression was downregulated by $\beta$-catenin knockout, while it was upregulated by $\beta$-catenin stabilization by exon 3 deletion or treatment with CHIR99021. Among Wnt ligands, Wnt5a, Wnt5b, and Wnt9a were highly expressed in SFZ cells, and recombinant human WNT5A and WNT5B stimulated Prg4 expression. Mechanical loading upregulated expression of these ligands and further promoted Prg4 transcription. Moreover, mechanical loading and Wnt/ß-catenin signaling activation increased mRNA levels of Creb1, a potent transcription factor for Prg4.

Conclusions: We demonstrated that Wnt/ $\beta$-catenin signaling regulates Prg4 expression in the SFZ of mouse adult articular cartilage, which plays essential roles in the homeostasis of articular cartilage.

Keywords: Osteoarthritis, Chondrocyte, Superficial zone, Wnt signaling

\section{Introduction}

Osteoarthritis (OA), which involves articular cartilage degradation, is the most prevalent joint disorder. A large number of studies using genetically modified mice have revealed signaling pathways or molecules responsible for OA, such as a disintegrin-like metallopeptidase with a thrombospondin type 1 motif 5 , hedgehog signaling, syndecan-4, matrix

\footnotetext{
* Correspondence: tasaitou-tky@umin.ac.jp

'Sensory \& Motor System Medicine, Graduate School of Medicine, The University of Tokyo, 7-3-1 Hongo, Bunkyo-ku, Tokyo 113-8655, Japan Full list of author information is available at the end of the article
}

metalloproteinase-13, hypoxia-inducible factor 2-alpha, nuclear factor kappa-light-chain-enhancer of activated B cells, Notch signaling, and Wnt signaling [1-9]. However, the entirety of OA pathophysiology is not yet understood despite all of these findings.

Wnt is one of the most investigated signaling pathways in developmental biology and pathophysiology of various diseases. Wnt genes encode a family of about 20 small secreted proteins, which are highly conserved across various organisms [10]. Wnt receptor activation leads to signal transduction via three different pathways: a canonical

(c) The Author(s). 2019 Open Access This article is distributed under the terms of the Creative Commons Attribution 4.0 International License (http://creativecommons.org/licenses/by/4.0/), which permits unrestricted use, distribution, and 
Wnt/ $\beta$-catenin cascade, noncanonical planar cell polarity pathway, and the $\mathrm{Wnt} / \mathrm{Ca}^{2+}$ pathway [10]. Notably, the Wnt/ $\mathrm{W}$-catenin pathway is the best understood of these signaling cascades. When Wnt proteins are not bound to a receptor, a serine/threonine kinase complex that includes Axin, casein kinase 1 , and glycogen synthase kinase 3 beta (GSK-3 $\beta$ ) phosphorylates $\beta$-catenin, which can then be degraded by E3 ubiquitin ligases [10]. However, once Wnt proteins bind their receptors, the kinase complex is recruited to the receptor, which leads to the stabilization of $\beta$-catenin [10]. Subsequently, $\beta$-catenin translocates into the nucleus, binds to $\mathrm{T}$ cell factor/lymphoid enhancer factor (Tcf/Lef), and activates the transcription of target genes [10].

Regulation of chondrocyte generation and differentiation by the canonical Wnt/ $\beta$-catenin pathway has been extensively investigated using transgenic and tissue-specific knockout mice. Skeletal formation is severely impaired in mouse embryos by chondrocyte-specific constitutive activation of Wnt/ $\beta$-catenin signaling [11-13]. Interestingly, inactivation or inhibition of $\mathrm{Wnt} / \beta$-catenin signaling also leads to severe impairment of skeletal growth [14-16]. These findings indicate that $\mathrm{Wnt} / \beta$-catenin signaling activity is restrictively regulated in chondrocyte generation and differentiation during development [17]. Similarly, regulation of articular cartilage by $\mathrm{Wnt} / \beta$-catenin signaling is complicated and somewhat contradictory. Transgenic mice expressing an inhibitor of $\beta$-catenin and Tcf in chondrocytes displayed enhanced articular cartilage destruction [3]. However, stabilization of $\beta$-catenin in adult chondrocytes also enhanced OA progression [7]. Reasons underlying these contradictory findings have not yet been reported.

Recently, roles of articular cartilage superficial zone (SFZ) cells have been the focus of several studies. SFZ cells are thought to have different properties from chondrocytes in the deeper zone (DZ). SFZ cells produce lubricin (encoded by $\operatorname{Prg} 4$ ), a protein responsible for the lubrication of articular joints that contributes to the protection of articular cartilage $[18,19]$. In the newborn period, joints of Prg4-knockout mice appear normal [18]. However, as the mice aged, their joints exhibited early wear and increased friction compared with WT mice [19]. Previous studies have shown that Wnt/ $\beta$ catenin signaling is constitutively activated in the SFZ and required for SFZ formation during skeletal development [20, 21]. A recent cell tracking study using Prg4$\mathrm{Cre}^{E R T 2}$ mice further revealed that Prg4-expressing cells located at the joint surface in embryos or young mice include a progenitor population for mature DZ chondrocytes [22]. Based on these findings, we hypothesized that $\mathrm{Wnt} / \beta$-catenin signaling activity may contribute to the maintenance of the SFZ and further homeostasis of articular joints in adulthood similarly to the developmental period.
Herein, we describe roles of Wnt/ $/$-catenin signaling in the SFZ of adult articular cartilage. We examined Wnt/ $\mathrm{W}$ catenin signaling activity in the SFZ and its in vivo roles in OA development, using SFZ-specific $\beta$-catenin knockout or stabilization. We further investigated expression levels of Wnt ligands and the involvement of mechanical loading as upstream triggers.

\section{Methods \\ Mice}

All animal experiments were authorized by the Animal Care and Use Committee of The University of Tokyo. We also complied with all relevant ethical regulations. In each experiment, we compared the genotypes of littermates maintained in a C57BL/6J background. TOPGAL, Prg4$C r e^{E R T 2}$, Rosa26-tdTomato (Ai14), and Ctnnb1-flox mice were obtained from The Jackson Laboratory (Bar Harbor, ME) [22-24]. Ctnnb1-ex3-flox mice were generated as previously described [25].

\section{Histological analyses}

Tissue samples were fixed in $4 \%$ paraformaldehyde buffered with phosphate-buffered saline (PBS, pH 7.4) at $4{ }^{\circ} \mathrm{C}$ for 1 day. Specimens were decalcified with $10 \%$ EDTA (pH 7.4) at $4{ }^{\circ} \mathrm{C}$ for 2 weeks, embedded in paraffin, and $5-\mu \mathrm{m}$-thick sagittal sections were cut from specimens. Safranin O staining was performed in accordance with standard protocols. For immunohistochemistry, sections were incubated with antibodies against red fluorescence protein (RFP; 1:2000; 600-401-379, Rockland, Limerick, PA), Ctnnb1 (1:1000, Ab2365, Abcam, Cambridge, UK), and Prg4 (1:500, Ab28484, Abcam). For visualization, simple stain mouse-MAX-PO(R) (Nichirei Bioscience, Tokyo, Japan) was used.

\section{Osteoarthritis (OA) experiments}

For OA experiments, Prg4-Cre ${ }^{E R T 2} ; \mathrm{Ctnnb}^{\mathrm{fl} / \mathrm{fl}}$ and Prg4$C r e^{E R T 2} ; C t n n b 1-e x 3^{f l / w t}$ mice were generated by mating

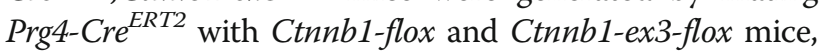
respectively. Tamoxifen (Sigma Aldrich, St. Louis, MO; $100 \mu \mathrm{g}$ per $\mathrm{g}$ of body weight) was intraperitoneally injected into 7-week-old Prg4-Cre ${ }^{E R T 2}$; $C$ tnnb1 $1^{f l / f l}, C t n n b 1^{f l f l}, \operatorname{Prg} 4$ $C r e^{E R T 2} ; C t n n b 1-e x 3^{f l w t}$, and Ctnnb1-ex $3^{f l / w t}$ mice daily for 5 days. A surgical procedure was then performed to establish an experimental OA model in 8-week-old male mice [26]. Under general anesthesia, resection of the medial collateral ligament and medial meniscus was performed under a surgical microscope. For sham surgery, only the skin incision was performed. Mice were analyzed 8 weeks after surgery. For the aging model, Prg4-Cre ${ }^{E R T 2} ; C t n n b f^{f l / f l}$ and $C$ tnnbilf $1^{f l / f l}$ mice were analyzed at 18 months of age. All mice were maintained under the same conditions (three mice per cage). OA severity was quantified using the Osteoarthritis Research Society International (OARSI) 
system [27], which was assessed by two observers blinded to the experimental groups.

\section{Cell cultures}

Primary SFZ cells were isolated as previously described [21]. Briefly, the primary end of the femur and the distal end of the tibia were dissected from P5 mice, and ligaments and tendons were excised. Cartilage tissues were incubated with $0.25 \%$ trypsin (Thermo Fisher Scientific, Waltham, MA) for $1 \mathrm{~h}$, followed by 1.5 -h digestion with $173 \mathrm{U} / \mathrm{mL}$ of type I collagenase (Worthington Biochemical Corporation, Lakewood, NJ). DZ cells were isolated by additional digestion of residual epiphyseal cartilage tissue with $43 \mathrm{U} / \mathrm{ml}$ collagenase type I for $5 \mathrm{~h}$. Dissociated cells were seeded on fibronectin-coated culture dishes. Cells were cultured with Dulbecco's modified Eagle's medium (DMEM) (Wako, Osaka, Japan) containing $10 \%$ fetal bovine serum (FBS). The cells were cultured as a monolayer in all experiments. We used $2 \mu \mathrm{M}$ 4-hydroxytamoxifen (4OHT; Sigma Aldrich, St Louis, MO, USA) to induce Cre recombination in the cultured SFZ cells. Recombinant human (rh) WNT5A (R\&D Systems, Minneapolis, MN), rhWNT5B (R\&D Systems), rhWNT9A (R\&D Systems), CHIR99021 (Cayman, Ann Arbor, MI), FH535 (Cayman), and 666-15(Tocris Bioscience, Bristol, UK) were used at the concentrations described in the figures and figure legends. For the luciferase assay, ATDC5 cells (Riken BRC, Tsukuba, Japan) were cultured in DMEM/F-12 (Wako) containing 5\% FBS.

\section{Cyclic tensile strain loading of mouse primary SFZ cells}

Mouse primary SFZ cells were seeded on silicon stretch chambers at a density of $1 \times 10^{5}$ cells/chamber (chamber area $=2 \times 2 \mathrm{~cm}$ ). The cells were cultured in DMEM containing 10\% FBS. Cyclic tensile strain $(0.5 \mathrm{~Hz}, 15 \%$ elongation) was applied by an STB-140 mechanical stretch system (STREX, Osaka, Japan) in a $\mathrm{CO}_{2}$ incubator. Control cells were cultured without cyclic tensile strain.

\section{Fluid flow shear stress (FFSS) conditions of mouse primary SFZ cells}

Mouse primary SFZ cells were seeded on tissue culture plates (culture plate diameter $=3.5 \mathrm{~cm}$ ) at a density of $2 \times 10^{5}$ cells $/ \mathrm{cm}^{2}$. The cells were cultured in DMEM containing 10\% FBS. FFSS (180 rotations per minute) was applied by a WB-101SRC orbital shaker (WAKEN, Kyoto, Japan) in a $\mathrm{CO}_{2}$ incubator. Control cells were cultured under a static condition.

\section{Western blotting}

Cells were lysed in M-PER mammalian protein extraction reagent (Thermo Fisher Scientific). Cell lysates were fractionated by SDS-PAGE and transferred onto nitrocellulose membranes (Bio-Rad, Hercules, CA). After blocking with $6 \%$ skim milk, membranes were incubated with primary antibodies against Ctnnb1 (1:250; \#9652, Cell Signaling Technology, Danvers, MA), CREB1 (1:250; 9197S, Cell Signaling Technology), and actin (1:250; AC-74, Sigma Aldrich). Membranes were incubated with a horseradish peroxidase-conjugated antibody (Promega, Madison, WI), and immunoreactive proteins were visualized with ECL prime (GE Healthcare, Chicago, IL) and iBright CL 1000 (Thermo Fisher Scientific). The signal intensity of three independent experiments was quantified using the iBright CL 1000 and normalized to actin.

\section{RT-qPCR}

Total RNA was purified with an RNeasy Mini Kit (Qiagen, Hilden, Germany). One microgram of total RNA was reverse transcribed using ReverTraAce qPCR RT Master Mix with gDNA Remover (Toyobo, Osaka, Japan). Each PCR reaction contained $1 \times$ THUNDERBIRD SYBR qPCR Mix (Toyobo), $0.3 \mathrm{mM}$ specific primers, and $20 \mathrm{ng}$ of cDNA. The full-length or partial cDNAs of target genes, including PCR amplicon sequences, were amplified by PCR, cloned into pCR-TOPO Zero II or pCR-TOPO II vectors (Invitrogen), and used as standard templates after linearization. Copy numbers of target mRNAs in each total RNA were calculated by reference to standard curves and adjusted to mouse standard total RNA (Thermo Fisher Scientific) with rodent actin as an internal control. All reactions were run in triplicate. Primer sequences for real-time RT-PCR are shown in Additional file 1: Table S1.

\section{Luciferase assay}

Proximal regions around the transcription start site of Prg4 (from $-3460,-1470$, or -500 to +592 bp relative to the transcription start site) were amplified by PCR using mouse genomic DNA as the template and cloned into the PGL4.10[luc2] vector (Promega). We performed the luciferase assay using ATDC5 cells and a Dual-Luciferase Reporter Assay System (Promega) and reported the data as the ratio of firefly to Renilla activities.

\section{Statistical analyses}

To assess the statistical significance of experimental data, we used a two-tailed unpaired Student's $t$ test for comparison of two groups, one-way ANOVA followed by Tukey's correction for comparison of multiple groups, and the Mann-Whitney $U$ test for the OARSI score, as appropriate. $P$ values less than 0.05 were considered significant. 


\section{Results}

\section{Wnt/ $\beta$-catenin signaling activity in the SFZ}

We initially confirmed Wnt/ $\beta$-catenin signaling activity in articular cartilage of adult mice. In knee joint cartilage of TOPGAL reporter mice, in which a $\beta$-galactosidase reporter is driven by $\beta$-catenin/Lef1-responsive elements, $\mathrm{X}$-Gal staining was detected in SFZ cells but not chondrocytes of middle and deep zones (Fig. 1a). Prg4, a representative marker protein for the SFZ, was determined to be expressed in a similar area by immunohistochemistry (Fig. 1b). We next examined localization of Cre expression in Prg4$C r e^{E R T 2}$ mice by mating them with Ai14 mice for further experiments. In frozen sections of $\operatorname{Prg} 4-\mathrm{Cre}^{E R T 2}$;Ai14 knee joint 1 week after tamoxifen induction, fluorescent signal was detected in the SFZ (Fig. 1c). After fixation and paraffin embedding, we confirmed Cre recombination by immunohistochemistry with an antibody against RFP. RFP protein was intensively detected in the SFZ of Prg4-Cre ${ }^{E R T 2}$;Ai14 knee joint after tamoxifen induction, whereas it was scarcely detected in animals without tamoxifen induction (Fig. 1d).

\section{Enhancement of OA development by $\beta$-catenin knockout} in the SFZ

We next examined roles of Wnt $/ \beta$-catenin in SFZ in vivo. To knockout $\beta$-catenin in Prg4-expressing cells in a tamoxifen-dependent manner, we generated Prg4$C r e^{E R T 2} ; C t n n b 1^{f l f l}$ mice by mating Prg4-Cre $e^{E R T 2}$ and Ctnnb1 ${ }^{f l / f l}$ mice. We injected tamoxifen into 7-week-old

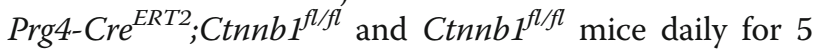
days. At 8 weeks, we created an OA model by surgical destabilization of knee joints [26]. Eight weeks after surgical induction, degradation of articular cartilage was significantly enhanced in $\operatorname{Prg} 4-C r e^{E R T 2} ; C t n n b 1^{f l / f l}$ mice (Fig. 2a), while the sham joints of both genotypes were similar (Additional file 2: Figure S1). Prg4 expression was decreased in the articular cartilage of sham joints in $\operatorname{Prg} 4-C r e^{E R T 2} ; C_{t n n b 1}{ }^{f l / f l}$ mice, as was $\beta$-catenin expression (Fig. 2b). We further investigated alterations of articular cartilage with age using these mice. Similar to the results of a surgical model, OA development was significantly accelerated in $\operatorname{Prg} 4-C r e^{E R T 2} ; \operatorname{Ctnnb} 1^{f l / f l}$ mice

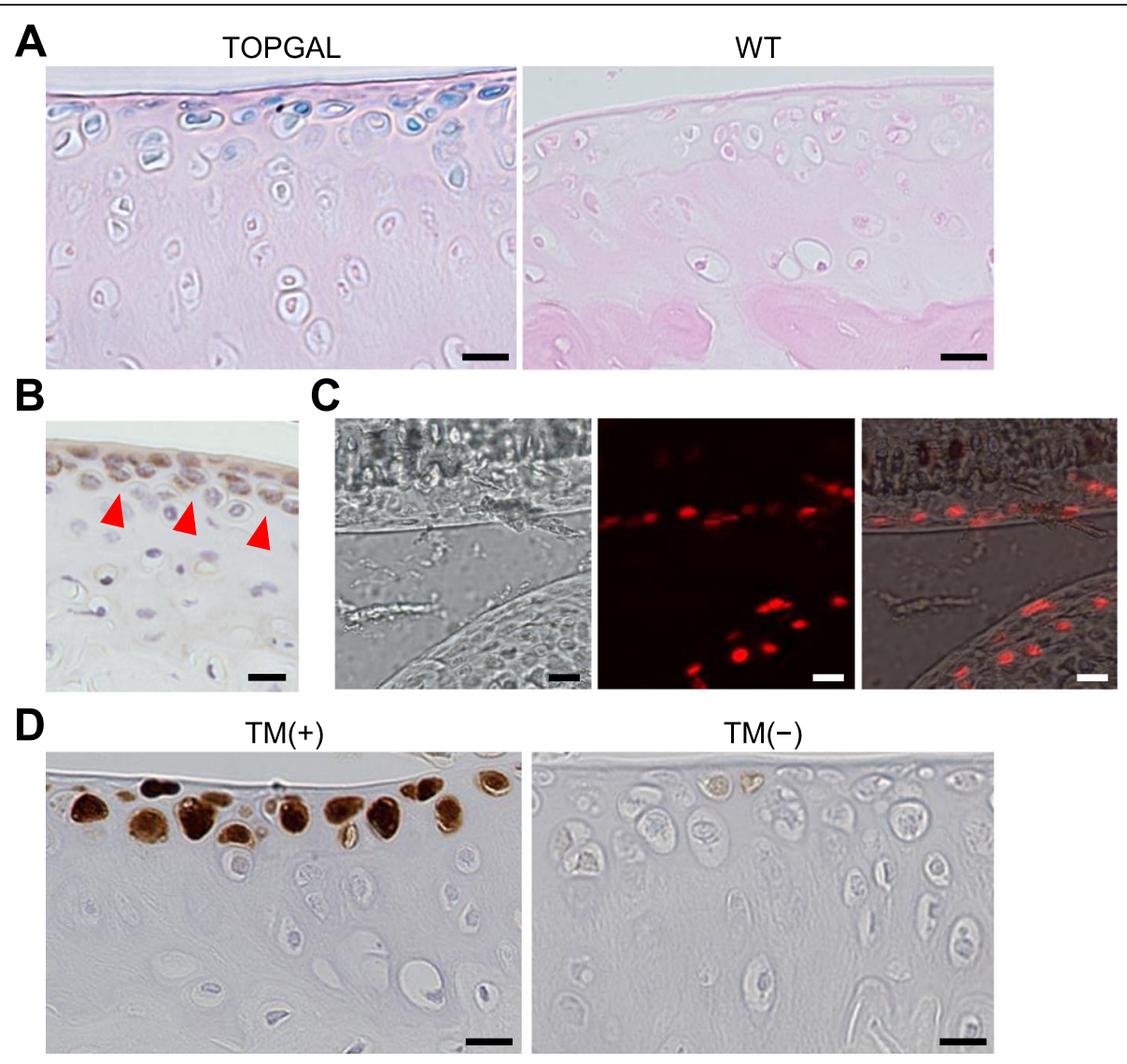

Fig. 1 Activity of Wnt/ß-catenin signaling in the superficial zone (SFZ) of mouse adult articular cartilage. a LacZ staining of tibial articular cartilage of 12-week-old TOPGAL and WT mice. Scale bars, $20 \mu \mathrm{m}$. b Immunostaining of lubricin (Prg4) in tibial articular cartilage of 12-week-old WT mice. Scale bar, $20 \mu \mathrm{m}$. Red arrowheads indicate positive areas. c Bright field and fluorescent images of a knee joint of 12-week-old Prg4-Cre ${ }^{E R T 2}$;Ait4 mouse 3 days after tamoxifen treatment. Scale bars, $20 \mu \mathrm{m}$. d Immunostaining of red fluorescent protein (RFP) in tibial articular cartilage of 12-week-old Prg4-Cre ${ }^{E R T 2}$;Ail4 mouse with [TM(+)] or without tamoxifen treatment $[\mathrm{TM}(-)]$. Scale bar, $20 \mu \mathrm{m}$ 


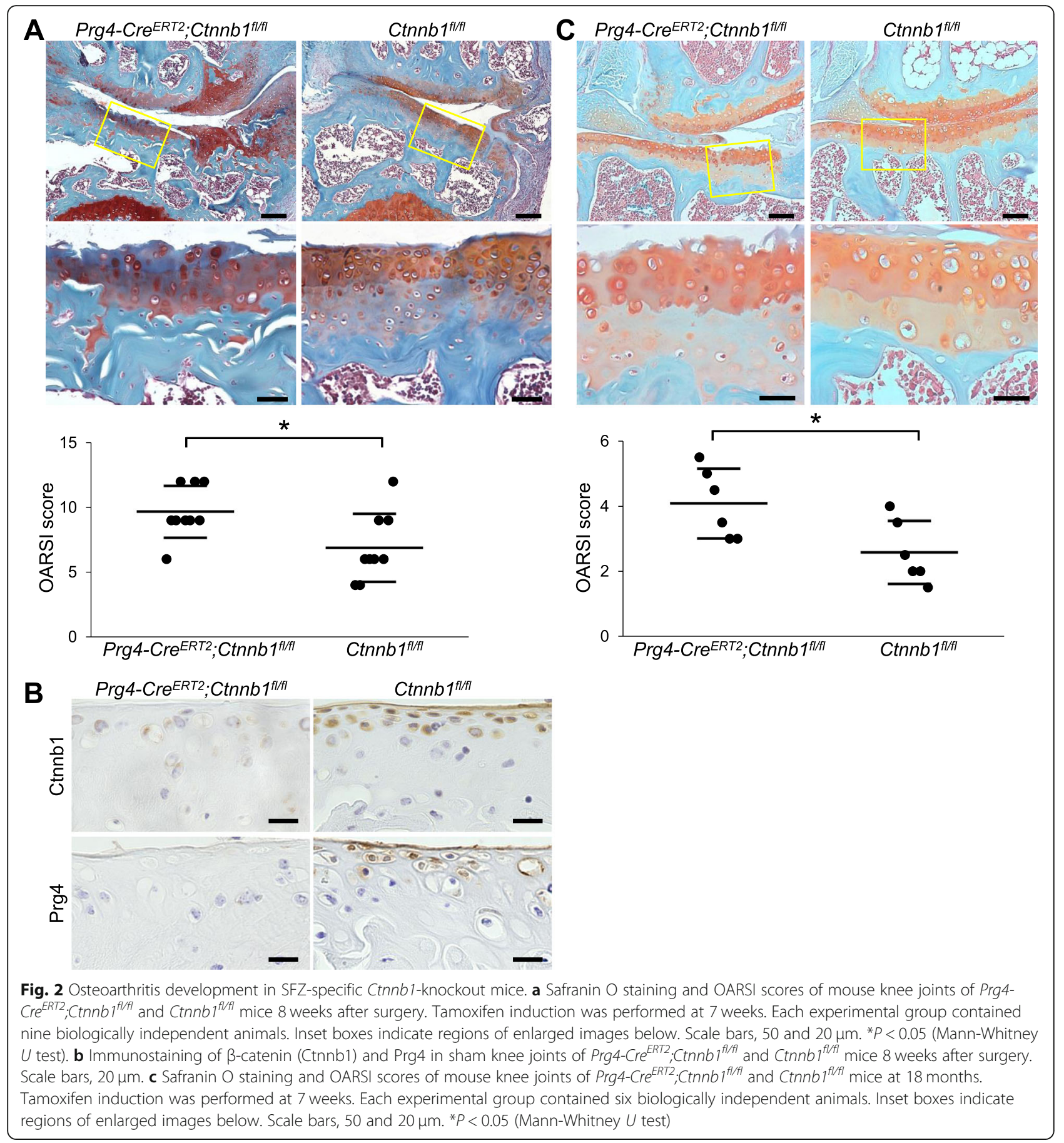

at 18 months (Fig. 2c). Notably, the SFZ of Prg4-Cre $e^{E R T 2}$; $C$ tnnb1 ${ }^{f l / f l}$ cartilage was markedly destructed (Fig. 2a, c).

\section{Suppression of OA development by $\beta$-catenin stabilization in the SFZ}

To examine gain-of-function, we prepared SFZ-specific $\beta$-catenin-stabilized mice by mating Prg4-Cre $e^{E R T 2}$ and Ctnnb1-ex $3^{f l / w t}$ mice. Deletion of exon 3 of the Ctnnb1 gene results in stabilization of $\beta$-catenin protein, as it becomes resistant to phosphorylation by GSK-3 $\beta$ [25]. We injected tamoxifen into 7-week-old Prg4-Cre ERT2 $^{E R}$ Ctnnb1-ex $3^{f l / w t}$ and Ctnnb1-ex $3^{f l / w t}$ littermates daily for 5 days and created a surgical OA model. At 8 weeks after surgical induction, OA development was significantly suppressed in Prg4-Cre ${ }^{E R T 2}$;Ctnnb1-ex $3^{f l / w t}$ mice (Fig. 3a). In addition, destruction of the SFZ was relatively suppressed in Prg4-Cre $e^{E R T 2} ; C t n n b 1-e x 3^{f l / w t}$ cartilage, although it was commonly observed in control cartilage 


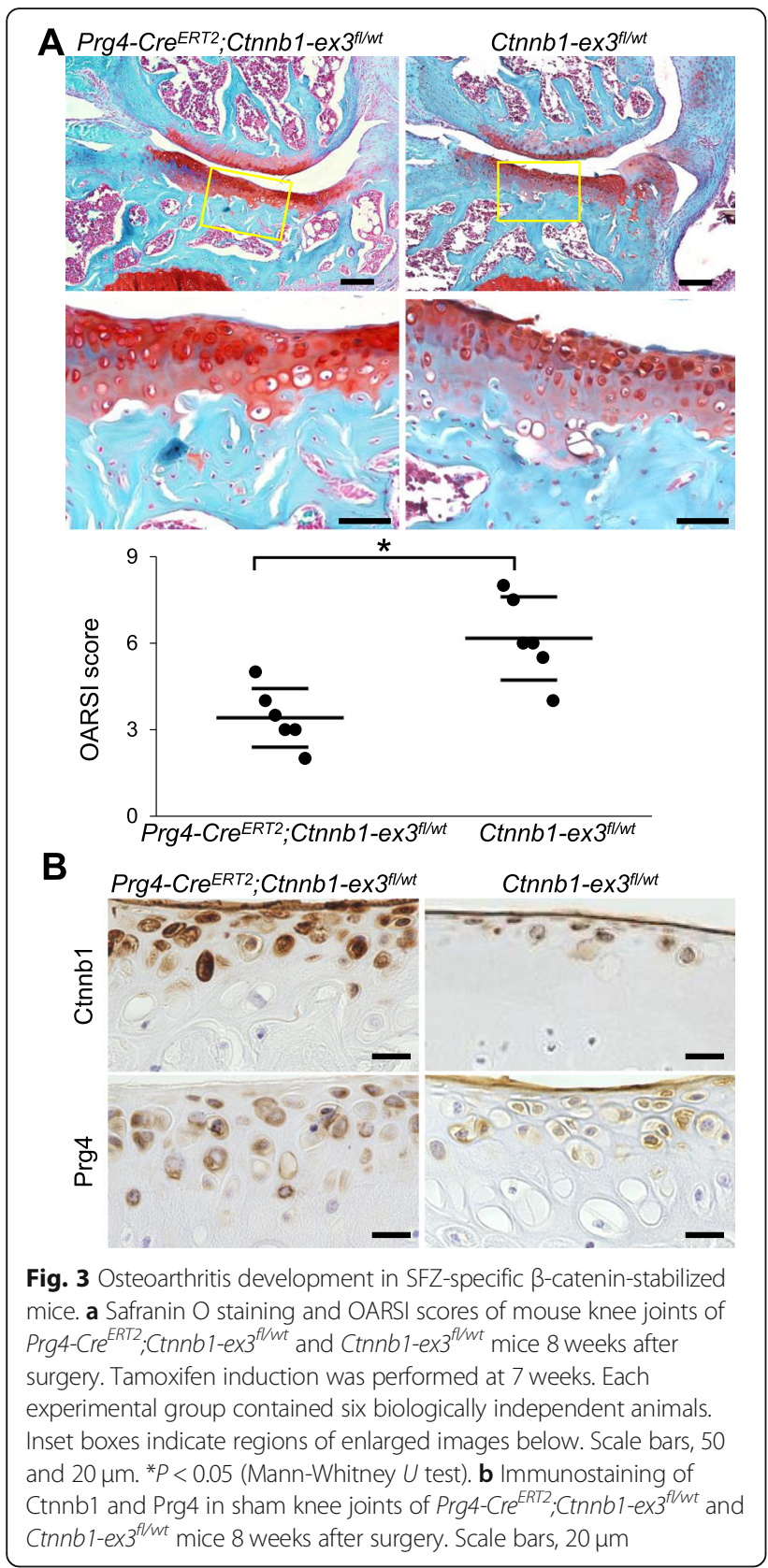

(Fig. 3a). The sham joints of both genotypes were similar (Additional file 2: Figure S1). $\beta$-catenin and Prg4 were both upregulated by the deletion of exon 3 of Ctnnb1 (Fig. 3b). Collectively, these in vivo data suggest that Wnt/ $\beta$-catenin signaling in the SFZ contributes to articular cartilage homeostasis.

\section{Regulation of Prg4 expression by Wnt/ $\beta$-catenin signaling} in the SFZ

We next examined the effects of Wnt/ $\beta$-catenin signaling in the SFZ with in vitro experiments using primary cells. We first confirmed appropriate isolation of SFZ cells by quantification of marker gene expression
(Additional file 3: Figure S2a, b). We then isolated SFZ cells from Prg4-Cre $e^{E R T 2} ; \mathrm{Ctnnb1}^{f l / f l}$ and Prg4-Cre ${ }^{E R T 2}$; Ctnnb1-ex ${ }^{f l / w t}$ mice as previously described [21] and treated the cells with $4 \mathrm{OHT}$ to induce Cre recombination. Western blotting and RT-qPCR confirmed downregulation of $\beta$-catenin in 4OHT-treated Prg4-Cre $e^{E R T 2}$; $C_{\text {tnnb1 }}{ }^{f l f l}$ cells (Fig. 4a). Moreover, mRNA levels of Prg4 were significantly decreased by $\beta$-catenin knockdown, while expression of aggrecan (Acan), a representative matrix gene in mature chondrocytes, was upregulated (Fig. 4a). In contrast, $\beta$-catenin expression was upregulated by $4 \mathrm{OHT}$ in Prg4-Cre ${ }^{E R T 2}$; Ctnnb1-ex $3^{f l / w t}$ cells (Fig. 4b), which exhibited significantly increased Prg4 expression and $\beta$-catenin stabilization and decreased Acan expression (Fig. 4b). We next treated SFZ cells from WT mice with CHIR99021, a GSK-3 $\beta$ inhibitor that is widely used as an activator of Wnt/ $\beta$-catenin signaling. Prg4 was upregulated and Acan was downregulated by CHIR99021 treatment, which was accompanied by increased $\beta$-catenin (Fig. 4c); this effect was also observed in 4OHT-treated Prg4-Cre $e^{E R T 2}$;Ctnnb1$e x 3^{f l / w t}$ cells (Fig. 4b). In addition, when we applied CHIR99021 to organ culture of mouse femoral heads, Prg4 expression was intensively enhanced (Fig. 4d).

\section{Activation of $\mathrm{Wnt} / \beta$-catenin signaling by mechanical loading}

We further examined triggers of Wnt/ $\beta$-catenin signaling activation in the SFZ. First, mRNA levels of representative Wnt ligands were examined in SFZ cells. $W n t 5 a, W n t 5 b$, and Wnt9a were abundantly expressed in SFZ cells, while expression levels of other Wnt ligands were low (Fig. 5a). We next examined the effects of mechanical loading, as Prg4 induction and Wnt/ $\beta$-catenin signaling activity are affected by mechanical loading $[28,29]$. We applied cyclic tensile strain to SFZ cells for 0-4h. mRNA levels of Prg4, Ctnnb1, and Axin2 began to increase at $1 \mathrm{~h}$, peaked at $2 \mathrm{~h}$, and decreased thereafter (Fig. 5b). mRNA levels of Wnt5a and Wnt5b were upregulated from 1 to $4 \mathrm{~h}$, while $W n t 9 a$ was increased from 1 to $2 \mathrm{~h}$ (Fig. $5 \mathrm{~b}$ ). Alteration of Wnt16 expression was irregular throughout (Fig. 5b). These data indicate that mechanical loading is one trigger that stimulates Wnt/ $\beta$-catenin signaling, probably via induction of Wnt ligands. Treatment with rhWNT5A, rhWNT5B, or rhWNT9A enhanced Ctnnb1 and Axin2 expression in SFZ cells (Fig. 5c). However, Prg4 expression was significantly increased by rhWNT5A and rhWNT5B, but not by rhWNT9A (Fig. 5c).

\section{CREB1 induction by Wnt/ $\beta$-catenin signaling}

Finally, we investigated one potential mechanism underlying Prg4 induction by Wnt/ $\beta$-catenin signaling. To examine whether Prg4 is a direct transcriptional target 


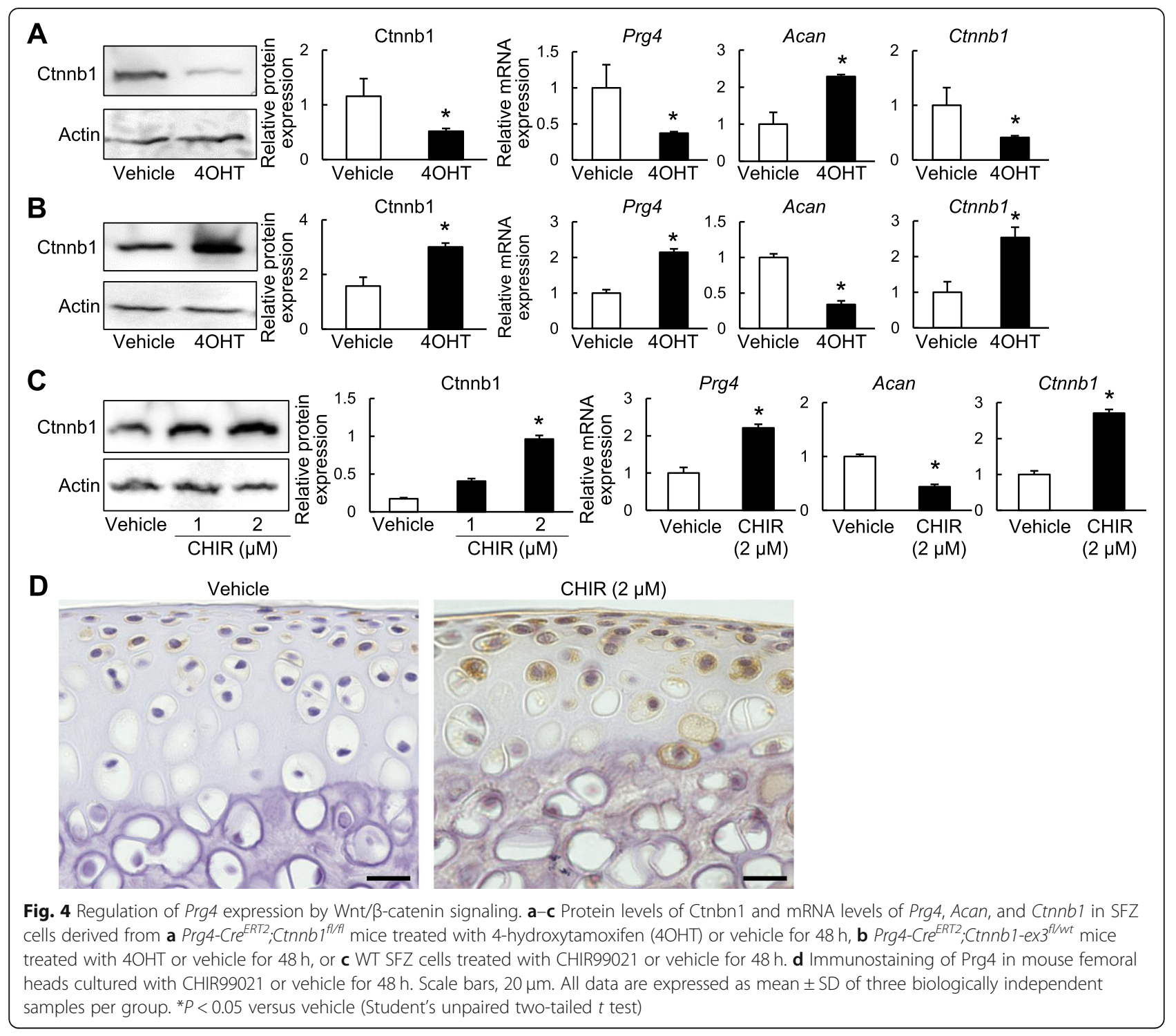

of the Lef- $\beta$-catenin complex, we performed a luciferase assay using three reporter vectors containing proximal regions around the transcription start site of Prg4. Overexpression of a constitutively active Lef1 (Lef1-CA) did not enhance transactivation of any Prg4 reporter (Fig. 6a). We next examined CREB1, which is already known as a potent upstream transcription factor of the Prg4 gene [28]. Notably, Creb1 expression was increased by cyclic tensile strain (Fig. 6b) in a similar pattern to Prg4 (Fig. 5c). CREB1 protein was also increased $2 \mathrm{~h}$ after stress loading, as was $\beta$-catenin (Fig. 6b). Expression of CREB1 and Prg4 was also increased by FFSS in a similar pattern (Fig. 6c). Moreover, CREB1 expression was enhanced by CHIR99021 treatment at both mRNA and protein levels (Fig. 6d). The increase of CREB1 and Prg4 induced by FFSS was partially, but significantly, decreased by the Wnt/B-catenin signaling inhibitor FH535
(Fig. 6e). The Prg4 induction by CHIR99021 was also significantly attenuated by the CREB1 inhibitor 666-15 (Fig. 6f). These results suggest that CREB1 is associated with Prg4 induction by Wnt/ $\beta$-catenin signaling.

\section{Discussion}

The present study demonstrated that $\mathrm{Wnt} / \beta$-catenin signaling plays essential roles in the SFZ of adult articular cartilage. Indeed, Wnt/ $\beta$-catenin signaling is activated only in the SFZ of adult articular cartilage. Loss-offunction in Prg4-positive cells leads to enhanced OA development with degenerated SFZ, while gain-of-function results in resistance to OA. Prg4 expression is dependent on Wnt/ $\beta$-catenin signaling, and mechanical stress loading increases expression of Wnt ligands and Prg4 in SFZ cells. Wnt/ $\beta$-catenin signaling induces CREB1, a representative transcription factor of $\operatorname{Prg} 4$. Similar to previous 

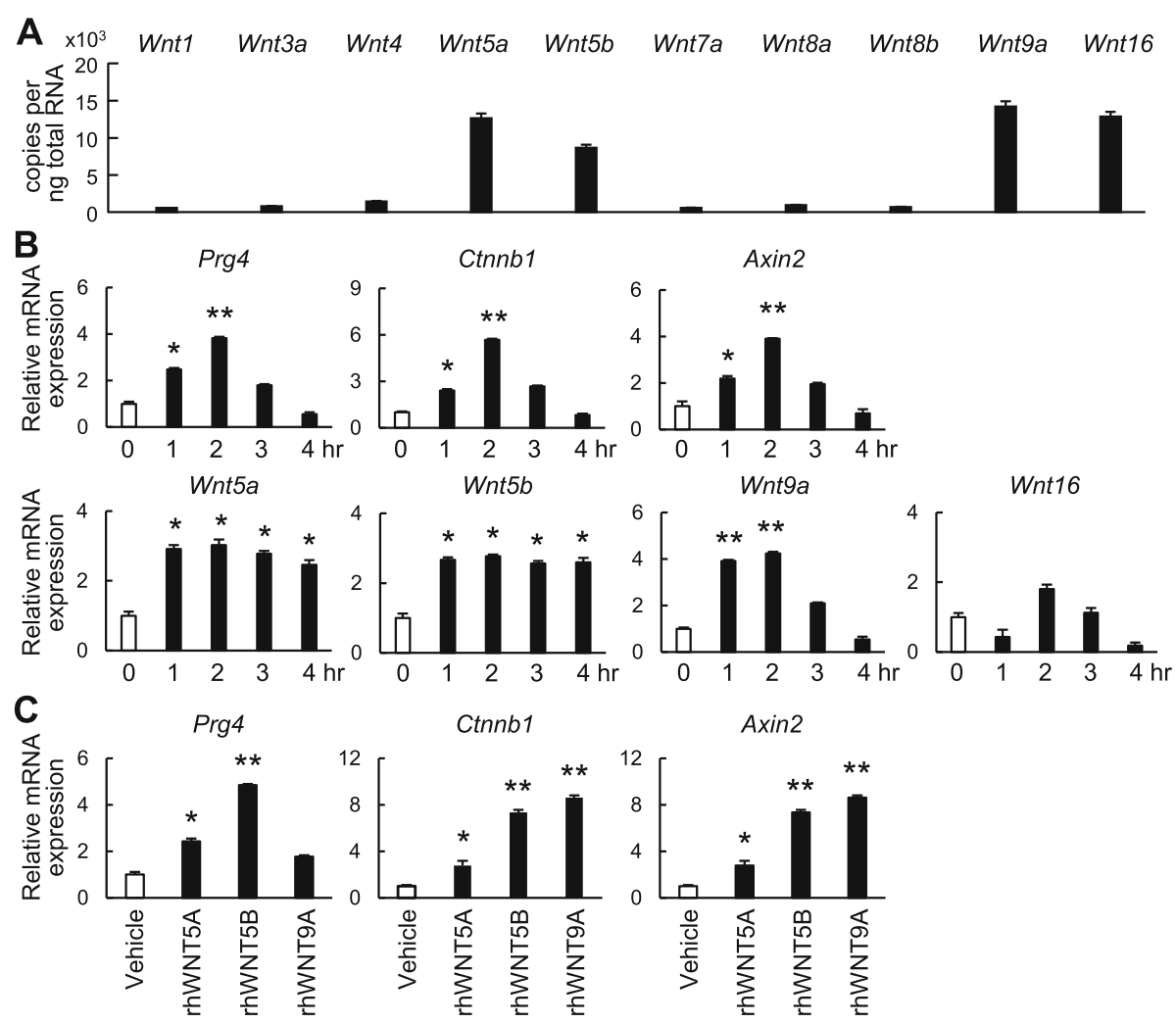

Fig. 5 Triggers of Wnt/B-catenin signaling in SFZ cells. a mRNA levels of Wnt ligands in SFZ cells. b mRNA levels of Prg4, Ctnnb1, Axin2, and Wnt ligands in SFZ cells loaded with cyclic tensile strain. c mRNA levels of Prg4, Ctnnb1, and Axin2 in SFZ cells treated with $100 \mathrm{ng} / \mathrm{ml}$ recombinant human (rh) WNT5A, WNT5B, WNT9A, or vehicle for 1 week. All data are expressed as mean \pm SD of three biologically independent samples per group. ${ }^{*} P<0.05$ and ${ }^{* *} P<0.01$ versus vehicle or $0 \mathrm{~h}$ (one-way ANOVA followed by Tukey's correction)

findings that $\mathrm{Wnt} / \beta$-catenin signaling contributes to characterization and formation of the SFZ during skeletal development [21], it is also necessary for the maintenance of adult articular cartilage.

Previous studies have shown that activation of Wnt/ $\mathrm{W}$ catenin signaling in chondrocytes enhances endochondral ossification and replacement by bone $[14,30]$. These findings are consistent with a previous report of enhanced OA progression in Col2a1-Cre $e^{E R T 2} ;$ Ctnnb1-ex ${ }^{\text {fllwt }}$ mice [7]. In this previous study, Safranin $\mathrm{O}$ and Alcian blue staining was reduced, and the articular cartilage area was reduced significantly in Col2a1-Cre $e^{E R T 2}$;Ctnnb1-ex $3^{\text {fllwt }}$ mice without surgical OA induction at 2 months after tamoxifen injection [7]. However, exacerbation of OA was also observed in transgenic mice expressing an inhibitor of $\beta$ catenin and Lef1 (ICAT) under the Col2a1 promoter [3]. The cartilage degeneration in transgenic mice was rather slow and mild, which may be partially because the binding of ICAT to $\beta$-catenin was not irreversible [3]. Notably, in Col2a1-ICAT mice, mild cartilage degeneration was observed at the articular surface, particularly in the weightbearing area of knee joints [3]. Considering that Col2a1 is expressed both in the SFZ and DZ, exacerbation of OA in Col2a1-ICAT mice may be associated with decreased activity of Wnt/B-catenin signaling in the SFZ, although Prg4 expression was not examined. In the present study, Prg4-Cre-driven $\beta$-catenin stabilization led to resistance against OA accompanied by enhanced expression of Prg4, whereas Prg4-Cre-driven $\beta$-catenin knockout resulted in OA exacerbation, indicating that $\mathrm{Wnt} / \beta$-catenin signaling in the SFZ contributes to cartilage homeostasis at least by Prg4 induction. A recent study showed that SFZ cells include a population of progenitors for articular chondrocytes [22]. Considering that $\mathrm{Wnt}$ is a major regulator of mesodermal cells [31], Wnt/ $\beta$-catenin signaling may be involved not only in Prg4 induction, but in maintenance of chondrocyte progenitors in the SFZ of adult articular cartilage.

The mechanisms underlying the high expression level of $\beta$-catenin protein in the SFZ are still unknown. We found that Wnt5a, Wnt5b, Wnt9a, and Wnt16 were highly expressed in SFZ cells (Fig. 5a). Among them, mRNA expression of Wnt5a, Wnt5b, and Wnt9a was induced by mechanical stress loading (Fig. 5b). However, we could not obtain further findings to explain the upregulation of Wnt/B-catenin signaling in the SFZ. Notably, a recent study showed that Wnt16 protects articular cartilage by antagonization of excessive Wnt/ $\mathrm{W}$ - 


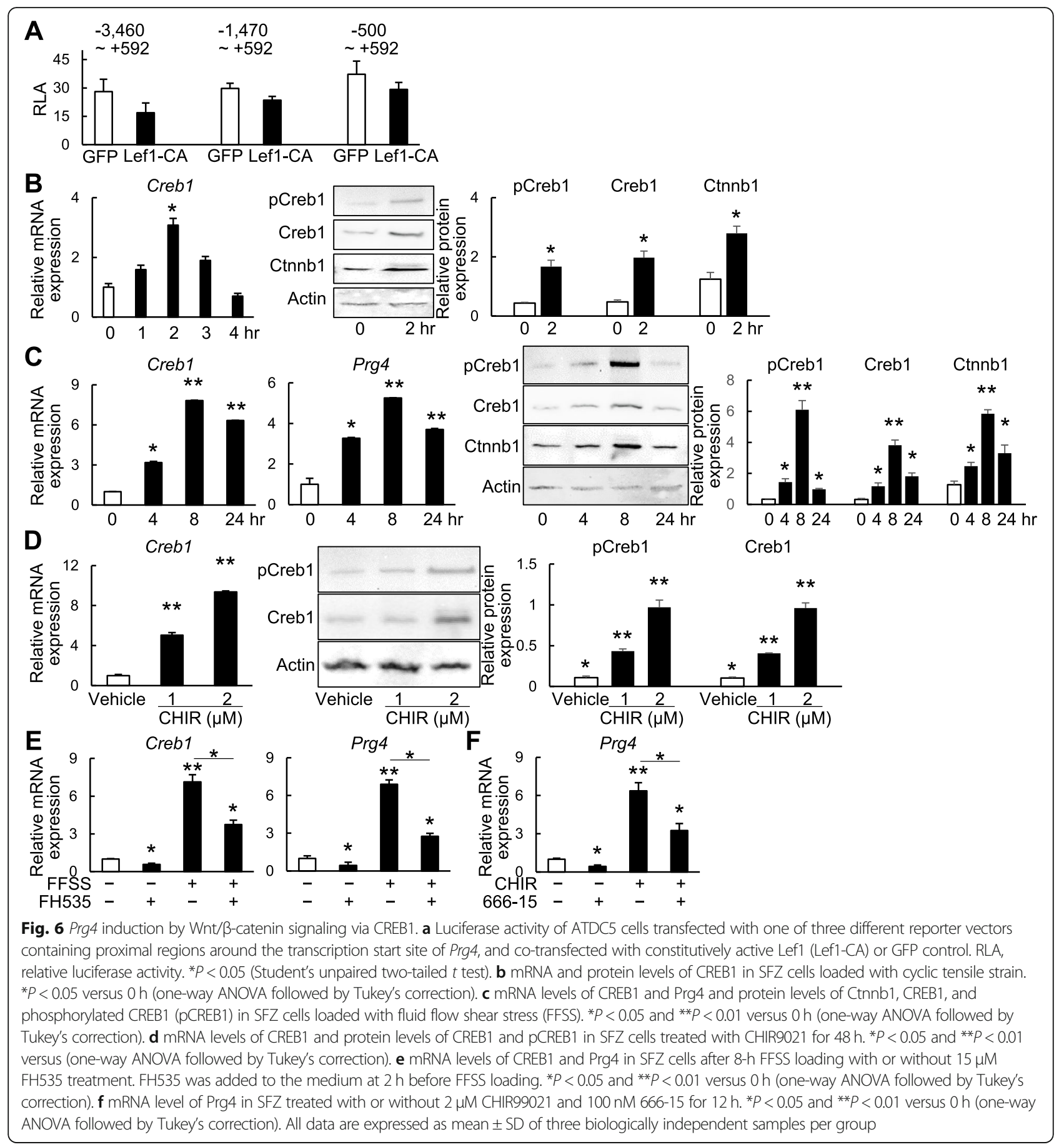

catenin signaling [32]. Wnt16 expression is increased in the SFZ during the early stage of mouse experimental knee OA [32]. Treatment with recombinant Wnt16 induces Prg4 expression, although the molecular pathway is unknown [32]. It is widely known that the potent Wnt antagonist FRZB is expressed in DZ chondrocytes and exerts cartilage-protective effects [33, 34]. Various molecules are likely to be involved in the tight regulation of $\mathrm{Wnt} / \beta$-catenin signaling in the SFZ.
CREB, a member of the leucine zipper family of DNA binding proteins, was identified as a protein that binds to the cAMP-responsive element [35]. Generally, transcriptional activity of CREB is regulated by phosphorylation [36]. Notably, in the present study, Creb1 mRNA expression was induced by $\mathrm{Wnt} / \beta$-catenin signaling. Although the interaction of Wnt/ $\beta$-catenin signaling and CREB-binding protein has been well described [37], induction of CREB by Wnt/ $\beta$-catenin signaling has not 
been revealed. However, as both CREB and Wnt/ $\beta$-catenin are widely expressed, the $\mathrm{Wnt} / \beta$-catenin-CREB pathway may be involved in other cell activities. We could not reveal the precise molecular mechanisms underlying transcriptional induction of CREB by Wnt/ $\beta$ catenin, i.e., whether the induction is direct or indirect. Furthermore, molecules or signaling pathways other than CREB may be also associated with Prg4 induction by Wnt/ $\beta$-catenin signaling.

Ogawa et al. previously reported that mechanical loading enhances Prg4 expression both in vivo and in vitro [28]. Their results indicated that FFSS induces Prg4 mainly via protein kinase A (PKA)/CREB signaling [28]. Enhanced prostaglandin E2 production and parathyroid hormone-related protein expression elicited CREB phosphorylation through PKA, resulting in increased Prg4 expression [28]. In their study, FFSS enhanced the activity of a luciferase reporter containing TCF-binding sites (TOP-luc), as well as CRE-luc [28]. Considering the present data, both enhanced CREB transcription induced by $W n t / \beta$-catenin and CREB phosphorylation induced by the PKA pathway are likely involved in Prg4 induction by mechanical loading.

\section{Conclusions}

In conclusion, we demonstrated that Wnt/ $\beta$-catenin signaling is activated specifically in the SFZ of adult mouse articular cartilage, whereby it contributes to Prg4 expression, which plays essential roles in the homeostasis of articular cartilage.

\section{Supplementary information}

Supplementary information accompanies this paper at https://doi.org/10 1186/s13075-019-2041-5.

\section{Additional file 1: Table S1. Primers used for RT-qPCR.}

Additional file 2: Figure S1. RepresentativeSafranin $O$ staining of sham knee joints in (a) Prg4-CreERT2; Ctnnb $1^{f / f l}$, Ctnnb1 $1^{f / / f}$, (b) Prg4-

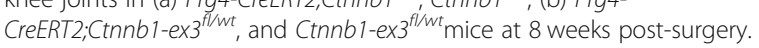

Tamoxifen induction was performed at 7 weeks. Insets indicate regions of enlarged images below. Scale bars, 50 and $20 \mu \mathrm{m}$.

Additional file 3: Figure S2. Validation of primary SFZ cells isolated from joints of P5 mice. a Morphology of SFZ cells and deeper zone (DZ) chondrocytes after 1 week of culture. Scale bars, $50 \mu \mathrm{m}$. b mRNA levels of marker genes in SFZ and DZ cells. ${ }^{*} P<0.05$ versus vehicle (Student's unpaired two-tailed t-test).

\section{Abbreviations \\ OA: Osteoarthritis; SFZ: Superficial zone; GSK-3ß: Glycogen synthase kinase 3 beta; Tcf/Lef: T cell factor/lymphoid enhancer factor; DZ: Deeper zone; PBS: Phosphate-buffered saline; RFP: Red fluorescence protein; OARSI: Osteoarthritis Research Society International; 4OHT: 4- Hydroxytamoxifen; rh: Recombinant human; Lef1-CA: Constitutively active Lef1; FFSS: Fluid flow shear stress; PKA: Protein kinase A}

\section{Acknowledgements}

We thank J. Sugita and K. Kaneko for the technical assistance. We also thank Edanz Group (www.edanzediting.com/ac) for editing a draft of this manuscript.

\section{Authors' contributions}

FX, FY, and TS conceived and designed the study. FX, FY, DM, RC, YM, YMaenohara, YMakii, and TO performed the experiment. FX, FY, MMT, HH, SO, UC, ST, and TS analyzed and interpreted the data. TS wrote the paper. All authors have read and approved the final manuscript.

\section{Funding}

This study was supported by JSPS KAKENHI Grant Numbers JP16K10888, JP19109007, JP17H04310, JP17K10996, and JP17K10998.

\section{Availability of data and materials}

The datasets analyzed during the current study are available from the corresponding author on reasonable request.

Ethics approval and consent to participate

All animal experiments were authorized by the Animal Care and Use Committee of The University of Tokyo (M-P17-091).

Consent for publication

Not applicable.

\section{Competing interests}

The authors declare that they have no competing interests.

\section{Author details}

${ }^{1}$ Sensory \& Motor System Medicine, Graduate School of Medicine, The University of Tokyo, 7-3-1 Hongo, Bunkyo-ku, Tokyo 113-8655, Japan. ${ }^{2}$ Bone and Cartilage Regenerative Medicine, Graduate School of Medicine, The University of Tokyo, 7-3-1 Hongo, Bunkyo-ku, Tokyo 113-8655, Japan. ${ }^{3}$ Division of Oral Anatomy, Department of Human Development and Fostering, Meikai University School of Dentistry, 1-1 Keyakidai, Sakado, Saitama 350-0283, Japan. ${ }^{4}$ Division of Experimental Therapeutics, Graduate School of Medicine, Kyoto University, Yoshida-Konoé-cho, Sakyo, Kyoto 606-8506, Japan. ${ }^{5}$ Center for Disease Biology and Integrative Medicine, Graduate School of Medicine, The University of Tokyo, 7-3-1 Hongo, Bunkyo-ku, Tokyo 113-8655, Japan.

Received: 1 May 2019 Accepted: 24 October 2019

Published online: 27 November 2019

\section{References}

1. Glasson SS, Askew R, Sheppard B, Carito B, Blanchet T, Ma HL, Flannery CR, Peluso D, Kanki K, Yang Z, et al. Deletion of active ADAMTS5 prevents cartilage degradation in a murine model of osteoarthritis. Nature. 2005; 434(7033):644-8.

2. Stanton H, Rogerson FM, East CJ, Golub SB, Lawlor KE, Meeker CT, Little CB, Last K, Farmer PJ, Campbell IK, et al. ADAMTS5 is the major aggrecanase in mouse cartilage in vivo and in vitro. Nature. 2005;434(7033):648-52.

3. Zhu M, Chen M, Zuscik M, Wu Q, Wang YJ, Rosier RN, O'Keefe RJ, Chen D. Inhibition of beta-catenin signaling in articular chondrocytes results in articular cartilage destruction. Arthritis Rheum. 2008:58(7):2053-64.

4. Echtermeyer F, Bertrand J, Dreier R, Meinecke I, Neugebauer K, Fuerst M, Lee YJ, Song YW, Herzog C, Theilmeier G, et al. Syndecan-4 regulates ADAMTS-5 activation and cartilage breakdown in osteoarthritis. Nat Med. 2009;15(9): 1072-6.

5. Lin AC, Seeto BL, Bartoszko JM, Khoury MA, Whetstone H, Ho L, Hsu C, Ali SA, Alman BA. Modulating hedgehog signaling can attenuate the severity of osteoarthritis. Nat Med. 2009:15(12):1421-5.

6. Little CB, Barai A, Burkhardt D, Smith SM, Fosang AJ, Werb Z, Shah M, Thompson EW. Matrix metalloproteinase 13-deficient mice are resistant to osteoarthritic cartilage erosion but not chondrocyte hypertrophy or osteophyte development. Arthritis Rheum. 2009;60(12):3723-33.

7. Zhu M, Tang D, Wu Q, Hao S, Chen M, Xie C, Rosier RN, O'Keefe RJ, Zuscik $M$, Chen D. Activation of beta-catenin signaling in articular chondrocytes leads to osteoarthritis-like phenotype in adult beta-catenin conditional activation mice. J Bone Mineral Res. 2009;24(1):12-21.

8. Saito T, Fukai A, Mabuchi A, Ikeda T, Yano F, Ohba S, Nishida N, Akune T, Yoshimura N, Nakagawa T, et al. Transcriptional regulation of endochondral ossification by HIF-2alpha during skeletal growth and osteoarthritis development. Nat Med. 2010;16(6):678-86. 
9. Yang S, Kim J, Ryu JH, Oh H, Chun CH, Kim BJ, Min BH, Chun JS. Hypoxiainducible factor-2alpha is a catabolic regulator of osteoarthritic cartilage destruction. Nat Med. 2010;16(6):687-93.

10. Clevers $\mathrm{H}$. Wnt/beta-catenin signaling in development and disease. Cell. 2006;127(3):469-80.

11. Akiyama H, Lyons JP, Mori-Akiyama Y, Yang X, Zhang R, Zhang Z, Deng JM, Taketo MM, Nakamura T, Behringer RR, et al. Interactions between Sox9 and beta-catenin control chondrocyte differentiation. Genes Dev. 2004;18(9): 1072-87.

12. Guo X, Day TF, Jiang X, Garrett-Beal L, Topol L, Yang Y. Wnt/beta-catenin signaling is sufficient and necessary for synovial joint formation. Genes Dev. 2004;18(19):2404-17.

13. Tamamura Y, Otani T, Kanatani N, Koyama E, Kitagaki J, Komori T, Yamada Y, Costantini F, Wakisaka S, Pacifici M, et al. Developmental regulation of Wnt/beta-catenin signals is required for growth plate assembly, cartilage integrity, and endochondral ossification. J Biol Chem. 2005;280(19):19185-95.

14. Day TF, Guo X, Garrett-Beal L, Yang Y. Wnt/beta-catenin signaling in mesenchymal progenitors controls osteoblast and chondrocyte differentiation during vertebrate skeletogenesis. Dev Cell. 2005;8(5):739-50.

15. Hill TP, Spater D, Taketo MM, Birchmeier W, Hartmann C. Canonical Wnt/ beta-catenin signaling prevents osteoblasts from differentiating into chondrocytes. Dev Cell. 2005;8(5):727-38.

16. Hu H, Hilton MJ, Tu X, Yu K, Ornitz DM, Long F. Sequential roles of Hedgehog and Wnt signaling in osteoblast development. Development 2005;132(1):49-60

17. Usami Y, Gunawardena AT, Iwamoto M, Enomoto-Iwamoto M. Wnt signaling in cartilage development and diseases: lessons from animal studies. Lab Invest. 2016;96(2):186-96.

18. Rhee DK, Marcelino J, Baker M, Gong Y, Smits P, Lefebvre V, Jay GD, Stewart M, Wang H, Warman ML, et al. The secreted glycoprotein lubricin protects cartilage surfaces and inhibits synovial cell overgrowth. J Clin Invest. 2005; 115(3):622-31.

19. Jay GD, Torres JR, Rhee DK, Helminen HJ, Hytinnen MM, Cha CJ, Elsaid K Kim KS, Cui Y, Warman ML. Association between friction and wear in diarthrodial joints lacking lubricin. Arthritis Rheum. 2007:56(11):3662-9.

20. Koyama E, Shibukawa Y, Nagayama M, Sugito H, Young B, Yuasa T, Okabe T, Ochiai T, Kamiya N, Rountree RB, et al. A distinct cohort of progenitor cells participates in synovial joint and articular cartilage formation during mouse limb skeletogenesis. Dev Biol. 2008;316(1):62-73.

21. Yasuhara R, Ohta Y, Yuasa T, Kondo N, Hoang T, Addya S, Fortina P, Pacifici $\mathrm{M}$, Iwamoto M, Enomoto-Iwamoto M. Roles of beta-catenin signaling in phenotypic expression and proliferation of articular cartilage superficial zone cells. Lab Invest. 2011;91(12):1739-52.

22. Kozhemyakina E, Zhang M, lonescu A, Ayturk UM, Ono N, Kobayashi A, Kronenberg $\mathrm{H}$, Warman ML, Lassar AB. Identification of a Prg4-expressing articular cartilage progenitor cell population in mice. Arthritis Rheumatol. 2015;67(5):1261-73.

23. Brault V, Moore R, Kutsch S, Ishibashi M, Rowitch DH, McMahon AP, Sommer L, Boussadia O, Kemler R. Inactivation of the beta-catenin gene by Wnt1-Cre-mediated deletion results in dramatic brain malformation and failure of craniofacial development. Development. 2001;128(8):1253-64.

24. Madisen L, Zwingman TA, Sunkin SM, Oh SW, Zariwala HA, Gu H, Ng LL, Palmiter RD, Hawrylycz MJ, Jones AR, et al. A robust and high-throughput Cre reporting and characterization system for the whole mouse brain. Nat Neurosci. 2010;13(1):133-40.

25. Harada N, Tamai Y, Ishikawa T, Sauer B, Takaku K, Oshima M, Taketo MM. Intestinal polyposis in mice with a dominant stable mutation of the betacatenin gene. EMBO J. 1999;18(21):5931-42.

26. Kamekura S, Hoshi K, Shimoaka T, Chung U, Chikuda H, Yamada T, Uchida M, Ogata N, Seichi A, Nakamura K, et al. Osteoarthritis development in novel experimental mouse models induced by knee joint instability. Osteoarthr Cartil. 2005;13(7):632-41.

27. Glasson SS, Chambers MG, Van Den Berg WB, Little CB. The OARSI histopathology initiative - recommendations for histological assessments of osteoarthritis in the mouse. Osteoarthr Cartil. 2010;18(Suppl 3):S17-23.

28. Ogawa H, Kozhemyakina E, Hung HH, Grodzinsky AJ, Lassar AB. Mechanical motion promotes expression of Prg4 in articular cartilage via multiple CREBdependent, fluid flow shear stress-induced signaling pathways. Genes Dev. 2014:28(2):127-39.
29. Niu Q, Li F, Zhang L, Xu X, Liu Y, Gao J, Feng X. Role of the Wnt/betacatenin signaling pathway in the response of chondrocytes to mechanical loading. Int J Mol Med. 2016;37(3):755-62.

30. Kitagaki J, Iwamoto M, Liu JG, Tamamura Y, Pacifci M, Enomoto-Iwamoto M. Activation of beta-catenin-LEF/TCF signal pathway in chondrocytes stimulates ectopic endochondral ossification. Osteoarthr Cartil. 2003;11(1): 36-43.

31. Przybyla L, Lakins JN, Weaver VM. Tissue mechanics orchestrate Wntdependent human embryonic stem cell differentiation. Cell Stem Cell. 2016; 19(4):462-75.

32. Nalesso G, Thomas BL, Sherwood JC, Yu J, Addimanda O, Eldridge SE, Thorup AS, Dale L, Schett G, Zwerina J, et al. WNT16 antagonises excessive canonical WNT activation and protects cartilage in osteoarthritis. Ann Rheum Dis. 2017;76(1):218-26.

33. Lories RJ, Peeters J, Bakker A, Tylzanowski P, Derese I, Schrooten J, Thomas $J T$, Luyten FP. Articular cartilage and biomechanical properties of the long bones in Frzb-knockout mice. Arthritis Rheum. 2007:56(12):4095-103.

34. Mori Y, Chung UI, Tanaka S, Saito T. Determination of differential gene expression profiles in superficial and deeper zones of mature rat articular cartilage using RNA sequencing of laser microdissected tissue specimens. Biomed Res. 2014;35(4):263-70.

35. Montminy MR, Bilezikjian LM. Binding of a nuclear protein to the cyclic-AMP response element of the somatostatin gene. Nature. 1987;328(6126):175-8.

36. Barton K, Muthusamy N, Chanyangam M, Fischer C, Clendenin C, Leiden JM. Defective thymocyte proliferation and IL-2 production in transgenic mice expressing a dominant-negative form of CREB. Nature. 1996:379(6560):81-5.

37. Novak A, Dedhar S. Signaling through beta-catenin and Lef/Tcf. Cell Mol Life Sci. 1999:56(5-6):523-37.

\section{Publisher's Note}

Springer Nature remains neutral with regard to jurisdictional claims in published maps and institutional affiliations.

Ready to submit your research? Choose BMC and benefit from:

- fast, convenient online submission

- thorough peer review by experienced researchers in your field

- rapid publication on acceptance

- support for research data, including large and complex data types

- gold Open Access which fosters wider collaboration and increased citations

- maximum visibility for your research: over $100 \mathrm{M}$ website views per year

At BMC, research is always in progress.

Learn more biomedcentral.com/submissions 